Research article

\title{
MicroRNA expression profiling of male breast cancer
}

\author{
Matteo Fassan ${ }^{1,2}$, Raffaele Baffa ${ }^{1,6}$, Juan P Palazzo ${ }^{3}$, Joshua Lloyd ${ }^{3}$, Marco Crosariol'1, Chang- \\ Gong Liu 4 , Stefano Volinia ${ }^{4}$, Hannes Alder ${ }^{4}$, Massimo Rugge 2 , Carlo M Croce ${ }^{4}$ and \\ Anne Rosenberg ${ }^{5}$
}

\begin{abstract}
1Department of Urology, Thomas Jefferson University - Kimmel Cancer Center, 1112 College Building, 1025 Walnut Street, PA 19107, USA 2Department of Medical Diagnostic Sciences \& Special Therapies - II Pathology Unit, University of Padova, via Gabelli 61, Padova 35121, Italy 3Department of Pathology, Thomas Jefferson University - Kimmel Cancer Center, 279 Jefferson Alumni Hall, 1020 Locust Street, PA 19107, USA ${ }^{4}$ Comprehensive Cancer Center, Ohio State University, 400 West 12th Avenue, Columbus, OH 43210, USA

${ }^{5}$ Department of Surgery, Thomas Jefferson University - Kimmel Cancer Center, 620 Curtis Building, 1015 Walnut Street, PA 19107, USA

${ }^{6}$ Present address: Medimmune, One Medimmune Way, Gaithersburg, MD 20878, USA
\end{abstract}

Corresponding author: Raffaele Baffa, R_Baffa@mail.jci.tju.edu

Received: 22 Nov 2008 Revisions requested: 18 Feb 2009 Revisions received: 15 Jun 2009 Accepted: 10 Aug 2009 Published: 10 Aug 2009

Breast Cancer Research 2009, 11:R58 (doi:10.1186/bcr2348)

This article is online at: http://breast-cancer-research.com/content/11/4/R58

(c) 2009 Fassan et al.; licensee BioMed Central Ltd.

This is an open access article distributed under the terms of the Creative Commons Attribution License (http://creativecommons.org/licenses/by/2.0), which permits unrestricted use, distribution, and reproduction in any medium, provided the original work is properly cited.

\begin{abstract}
Introduction MicroRNAs (miRNAs) are a class of small noncoding RNAs that control gene expression by targeting mRNAs and triggering either translation repression or RNA degradation. Their aberrant expression may be involved in human diseases, including cancer. To test the hypothesis that there is a specific miRNA expression signature which characterizes male breast cancers, we performed miRNA microarray analysis in a series of male breast cancers and compared them with cases of male gynecomastia and female breast cancers.
\end{abstract}

Methods Paraffin blocks were obtained at the Department of Pathology of Thomas Jefferson University from 28 male patients including 23 breast cancers and five cases of male gynecomastia, and from 10 female ductal breast carcinomas. The RNA harvested was hybridized to miRNA microarrays $(\sim 1,100$ miRNA probes, including 326 human and 249 mouse miRNA genes, spotted in duplicate). To further support the microarray data, an immunohistochemical analysis for two specific miRNA gene targets (HOXD10 and VEGF) was performed in a small series of male breast carcinoma and gynecomastia samples.
Results We identified a male breast cancer miRNA signature composed of a large portion of underexpressed miRNAs. In particular, 17 miRNAs with increased expression and 26 miRNAs with decreased expression were identified in male breast cancer compared with gynecomastia. Among these miRNAs, some had well-characterized cancer development association and some showed a deregulation in cancer specimens similar to the one previously observed in the published signatures of female breast cancer. Comparing male with female breast cancer miRNA expression signatures, 17 significantly deregulated miRNAs were observed (four overexpressed and 13 underexpressed in male breast cancers). The HOXD10 and VEGF gene immunohistochemical expression significantly follows the corresponding miRNA deregulation.

Conclusions Our results suggest that specific miRNAs may be directly involved in male breast cancer development and that they may represent a novel diagnostic tool in the characterization of specific cancer gene targets.

\section{Introduction}

Breast cancer is a rare disease in men, representing less than $1 \%$ of all malignancies and responsible for $0.1 \%$ of male cancer deaths $[1,2]$. Despite its infrequent prevalence, male breast cancer can cause significant morbidity and mortality. In fact, it has a more aggressive clinical behavior compared with female breast cancer [2]. Most of the current knowledge regarding male breast cancer biology, natural history and treatment strategies is still limited and has been extrapolated from its female counterpart. 
Genome-wide microarray gene expression analysis has been largely used to characterize human cancers. This approach allowed the identification of genes important in tumorigenesis. Microarray tools have been recently enriched by the development of platforms for the analysis of microRNA (miRNA) expression [3,4]. miRNAs are $\sim 22$-nucleotide small noncoding RNAs that modulate gene expression by binding to target mRNA by imperfect complementary, causing either mRNA degradation or translation inhibition [5]. In humans, aberrant expression of miRNAs contributes to carcinogenesis by promoting the expression of proto-oncogenes or by inhibiting the expression of tumor suppressor genes. Such oncomirs have been demonstrated in a variety of hematologic and solid malignancies [6-8], and also in female breast cancer [9-31]. Furthermore, interfering with miRNA expression, an altered experimental tumorigenesis has been observed [14,32].

Indeed, genome-wide profiling integrated by functional studies that involve overexpression and downregulation of miRNAs represents the current approach that is most likely to yield advances in the new field of noncoding RNA research. Moreover, miRNAs are, in contrast to most mRNAs, long-lived in vivo and very stable in vitro, which might be critical in a clinical setting and may allow analysis of paraffin-embedded samples [11].

Previous studies have demonstrated that there is a large number of deregulated miRNAs in human breast cancer (in particular, miR-10b, miR-17-5p, miR-21, miR-27a, miR-27b, miR-125a, miR-125b, miR-126, miR-145, miR-155, miR200c, miR-206, miR-336 and the let-7 family) [9-31]. The miRNA signatures have been correlated with clinicopathological and prognostic parameters such as tumor size, nodal involvement, vascular invasiveness, ErbB2, estrogen receptor status and chemotherapy resistance [9-11,13,21$24,27,28,30,31]$. Moreover, a functional polymorphism in the miR-146a gene has been correlated with the predisposition to an earlier age of onset of familial breast and ovarian cancers [26]. Three recent studies proved the involvement of miRNAs in breast cancer metastases [14,32,33]. For instance, miR$10 \mathrm{~b}$ overexpression leads to tumor invasion and metastasis by suppressing HOXD10 and indirectly activating the prometastatic gene RHOC [14]. Two other miRNAs (miR-373 and miR-520c) can also promote tumor invasion and metastasis, at least in part by regulating the CD44 gene [32]. In addition, miR-335, miR-206 and miR-126 have been identified as suppressors of breast cancer metastasis [33].

These findings strongly suggest that miRNA expression profiles could represent a promising new class of cancer biomarkers. Moreover, in the future, miRNAs could be potentially used as innovative and targeted therapeutics [34].

In the present report we analyze the genome-wide miRNA expression profile of 23 male breast carcinoma cases versus five male gynecomastia cases, and of 10 female breast carcinoma samples. Our data indicate a miRNA signature associated with male breast carcinoma and suggest miRNA deregulation as an important event in male breast cell transformation.

\section{Materials and methods Tissue samples}

After exempt status for the study was granted by the Institutional Review Board of Thomas Jefferson University, specimens from 28 male patients, including 23 cases of breast cancer and five cases of gynecomastia, and from 10 female patients affected by ductal breast carcinoma were identified from the archival files of the Department of Pathology of Thomas Jefferson University (Philadelphia, PA, USA). The patients had undergone treatment by either simple mastectomy or wide local excision and radiotherapy. Adjuvant therapy was not given. All cases were reviewed by two pathologists (JPP and $\mathrm{RB}$ ) and the diagnoses confirmed. Four $15 \mu \mathrm{m}$ sections were obtained from each case.

For the immunohistochemical study, formalin-fixed and paraffin-embedded tissues of 10 cases of male ductal breast carcinoma and five cases of gynecomastia were obtained from the archival files of the Department of Surgical Pathology of the University of Padova.

All patients considered in this study gave their written informed consent. The male breast cancer samples have been considered in an earlier publication [35].

\section{MicroRNA microarray}

Tissue sections were deparaffinized with xylene at $50^{\circ} \mathrm{C}$ for 3 minutes. Total RNA extraction was undertaken using the RecoverAll kit (Ambion Inc, Austin, TX, USA) according to the manufacturer's instructions. RNA labeling and hybridization on miRNA microarray chips were performed as previously described [36]. Briefly, $5 \mu \mathrm{g}$ total RNA from each sample were reverse-transcribed using biotin end-labeled random-octamer oligonucleotide primer. Hybridization of biotin-labeled complementary DNA was performed on a new Ohio State University custom miRNA microarray chip (OSU_CCC version 4.0), which contains $\sim 1,100$ miRNA probes - including 326 human and 249 mouse miRNA genes, spotted in duplicate [3]. The hybridized chips were washed and processed to detect biotincontaining transcripts by streptavidin- Alexa647 conjugate and were scanned on an Axon 4000B microarray scanner (Axon Instruments, Sunnyvale, CA, USA).

\section{Statistical and bioinformatics analysis}

Microarray images were analyzed using GENEPIX PRO 6.0 (Axon Instruments). Average values of the replicate spots of each miRNA were background subtracted, normalized and further analyzed. Normalization was performed using quantiles [3]. The microarray data have been deposited at the National 
Center for Biotechnology Information Gene Expression Omnibus repository [GEO:GSE17155].

miRNAs that are differentially expressed between breast cancer and gynecomastia were identified using a random-variance $t$ test. The random-variance $t$ test is an improvement over the standard separate $t$ test as it permits sharing information among genes about within-class variation without assuming that all genes have the same variance [37]. Genes were considered statistically significant if their $P$ value was less than 0.01 . A stringent significance threshold was used to limit the number of false positive findings [38]. Only mature miRNAs that are differentially expressed are reported.

Our samples were not microdissected so, to further avoid the influence of heterogeneity/a different percentage of cell types between compared samples (cancer cells versus surrounding stromal tissue cells), we performed an enrichment analysis for the gynecomastia versus male breast cancer groups. The enrichment analysis was performed by enriching the original microarray analysis data for tumor area. For this purpose, the tumor area - defined as the percentage of tumor over the stromal counterpart - was histologically determined by two pathologists (JPP and RB).

\section{Quantitative real-time PCR}

The single-tube TaqMan miRNA Assay (Applied Biosystems, Foster City, CA, USA) was used to detect and quantify mature miRNAs on Applied Biosystems real-time PCR instruments in accordance with the manufacturer's instructions. Normalization was performed with the small nuclear RNA U48 (RNU48; Applied Biosystems). All real-time reactions, including no-template controls and real-time minus controls, were run in a GeneAmp PCR 9700 thermocycler (Applied Biosystems). Gene expression levels were quantified using the ABI Prism 7900HT Sequence Detection System (Applied Biosystems).

Comparative real-time PCR was performed in triplicate, including no-template controls. The fold difference for each sample was obtained using the expression $2-\Delta \mathrm{Ct}$, in which $\mathrm{Ct}$ is the threshold cycle (the threshold cycle is the cycle number at which the fluorescence generated within a reaction crosses the threshold) and $\Delta \mathrm{Ct}$ is the difference between the average $\mathrm{Ct}$ value of a sample gene and the average $\mathrm{Ct}$ for the endogenous reference RNU48. Total RNA from 19 of the 23 male breast cancers and from the five gynecomastia samples were used in the quantitative real-time PCR analysis. The RNA was extracted from different tissue blocks to those used in the miRNA microarray study.

\section{Immunohistochemistry}

Staining was performed automatically (Ventana Benchmark XT system; Ventana Medical Systems, Touchstone, AZ, USA) for vascular endothelial growth factor (VEGF) (catalog number sc-152 - VEGF-A20, 1:100; Santa Cruz Biotechnology Inc.,
Santa Cruz, CA, USA) and homeobox-D10 (HOXD10) (catalog number sc-66926, 1:50; Santa Cruz Biotechnology Inc.) according to the manufacturer's instructions. Sections were then lightly counterstained with hematoxylin. Appropriate positive and negative controls were run concurrently. The expression of each immunohistochemical (IHC) marker was jointly scored by two pathologists (MF and MR). Cytoplasmic positivity was considered for VEGF, and both cytoplasmic and membranous positivity were considered for HOXD10. Regarding the IHC score intensity, positive staining was semi-quantified with a three-tier system: negative positivity, low-grade positivity, high-grade positivity. Results were reported as positive when staining was observed in at least $5 \%$ of the tumor cells. When the staining intensity was heterogeneous, the highest result was retained for scoring.

\section{Results \\ MicroRNA expression signatures discriminate between gynecomastia and cancer and between male and female breast cancers}

To identify deregulated miRNAs in male breast cancers, the miRNA expression profiles were determined for five male gynecomastia samples, 23 male breast cancer samples and 10 female breast cancer samples using a custom microarray platform proven to give robust results, as validated by several studies $[3,4,10,12]$. All of the 23 male breast cancer samples pathologically corresponded to invasive ductal breast carcinoma. The clinicopathological characteristics are summarized in Table 1.

Comparison analysis showed the differential expression of several miRNA genes between gynecomastia and male breast cancer. In detail, we identified 17 miRNAs with increased expression and 26 miRNAs with decreased expression in male breast cancer samples in comparison with gynecomastia samples (Table 2).

Although our samples were partially microdissected, contamination by surrounding stromal cells was unavoidable. We therefore performed an enriched analysis for the tumor area (Table 3). miR-499-3p and miR-330-5p miRNA follow the enrichment, decreasing in the gynecomastia and increasing in the male breast cancer samples.

No significant association has been observed between clinicopathological tumor characteristics and miRNA gene expression.

In the search for male/female breast cancer specific miRNAs, we correlated male breast cancer with female breast cancer miRNA gene expression profiles. This sex-specific comparison showed a different expression of 17 miRNAs between the two categories, with four upregulated and 13 downregulated miRNAs in male breast cancers (Table 4 and Figure 1). 
Table 1

Clinicopathological characteristics of the $\mathbf{2 3}$ male breast cancer samples

\begin{tabular}{|c|c|}
\hline Characteristic & Value \\
\hline Age & $71.2 \pm 9.0(72.0)$ \\
\hline Tumor size & $20.0 \pm 9.6(20.0)$ \\
\hline \multicolumn{2}{|l|}{ Diagnosis } \\
\hline Invasive ductal carcinoma & $11(47.8 \%)$ \\
\hline Invasive ductal carcinoma + ductal carcinoma in situ & $12(52.2 \%)$ \\
\hline \multicolumn{2}{|l|}{ Nuclear grade } \\
\hline 1 & $3(13.0 \%)$ \\
\hline$\|$ & $11(47.8 \%)$ \\
\hline III & $9(39.1 \%)$ \\
\hline \multicolumn{2}{|l|}{ Histological grade } \\
\hline I & $2(8.7 \%)$ \\
\hline II & $12(52.2 \%)$ \\
\hline III & $9(39.1 \%)$ \\
\hline \multicolumn{2}{|l|}{ Cytokeratin $5 / 6$} \\
\hline 0 & $19(82.6 \%)$ \\
\hline+ & $1(4.3 \%)$ \\
\hline++ & $3(13.0 \%)$ \\
\hline+++ & $0(0.0 \%)$ \\
\hline \multicolumn{2}{|l|}{ Cytokeratin 14} \\
\hline 0 & $19(82.6 \%)$ \\
\hline+ & $2(8.7 \%)$ \\
\hline++ & $0(0.0 \%)$ \\
\hline+++ & $2(8.7 \%)$ \\
\hline \multicolumn{2}{|l|}{ Cytokeratin 18} \\
\hline 0 & $1(4.3 \%)$ \\
\hline+ & $0(0.0 \%)$ \\
\hline++ & $3(13.0 \%)$ \\
\hline+++ & $19(82.6 \%)$ \\
\hline \multicolumn{2}{|l|}{ pT } \\
\hline 1 & $13(56.5 \%)$ \\
\hline 2 & $10(43.5 \%)$ \\
\hline \multicolumn{2}{|l|}{$\mathrm{pN}$} \\
\hline 0 & $8(34.8 \%)$ \\
\hline 1 & $8(34.8 \%)$ \\
\hline 2 & $1(4.3 \%)$ \\
\hline$x$ & $6(26.1 \%)$ \\
\hline \multicolumn{2}{|l|}{ pM } \\
\hline 0 & $8(34.8 \%)$ \\
\hline 1 & $2(8.7 \%)$ \\
\hline$x$ & $13(56.5 \%)$ \\
\hline \multicolumn{2}{|l|}{ Estrogen receptors } \\
\hline Positive & $12(95.7 \%)$ \\
\hline Negative & $1(4.3 \%)$ \\
\hline Not available & 10 \\
\hline \multicolumn{2}{|l|}{ Progesterone receptors } \\
\hline Positive & $13(100.0 \%)$ \\
\hline Negative & $0(0.0 \%)$ \\
\hline Not available & 10 \\
\hline
\end{tabular}

Data presented as the mean \pm standard deviation (median) or as $n(\%)$. -, negative;,$+<25 \% ;++, 25$ to $50 \%$; and,$+++>50 \%$. 
Table 2

\begin{tabular}{|c|c|c|c|c|}
\hline MicroRNA & Cancer normalized & Gynecomastia normalized & Fold change ${ }^{a}$ & $P$ value \\
\hline hsa-miR-26a-2 & 82.5 & 15.4 & 5.357 & 0.002517 \\
\hline hsa-miR-26b & 137.7 & 27.2 & 5.062 & 0.006413 \\
\hline hsa-miR-499-3p & 290.6 & 63.9 & 4.548 & 0.005332 \\
\hline hsa-miR-607 & 389.4 & 87 & 4.476 & 0.001533 \\
\hline hsa-miR-135b & 199.3 & 45.7 & 4.361 & 0.008074 \\
\hline hsa-miR-616 & 269.9 & 66 & 4.089 & 0.008253 \\
\hline hsa-miR-769-5p & 184.4 & 53.6 & 3.44 & 0.006534 \\
\hline hsa-miR-330-5p & 291.1 & 89.2 & 3.263 & 0.001353 \\
\hline hsa-miR-132 & 155.7 & 49.2 & 3.165 & 0.007551 \\
\hline hsa-miR-149 & 461.7 & 161.6 & 2.857 & 0.003765 \\
\hline hsa-miR-557 & 686.1 & 286.4 & 2.396 & 0.005408 \\
\hline hsa-miR-29b-2 & $1,273.7$ & 604.9 & 2.106 & $1.12 \times 10^{-5}$ \\
\hline hsa-miR-657 & $2,499.3$ & $1,277.2$ & 1.957 & 0.000899 \\
\hline hsa-miR-483-3p & $18,985.9$ & $10,525.1$ & 1.804 & 0.001411 \\
\hline hsa-miR-371-3p & $9,741.4$ & $5,642.1$ & 1.727 & 0.003106 \\
\hline hsa-miR-593 & $1,805.1$ & $1,051.3$ & 1.717 & 0.001461 \\
\hline hsa-miR-596 & $1,430.8$ & 909.5 & 1.573 & 0.000370 \\
\hline hsa-miR-92a & $6,490.7$ & $11,614.8$ & -1.789 & 0.008752 \\
\hline hsa-miR-145 & $1,561.5$ & $3,649.3$ & -2.336 & 0.000110 \\
\hline hsa-miR-99b & 678.8 & $1,697.8$ & -2.500 & 0.000985 \\
\hline hsa-miR-214 & $1,392.7$ & $3,717.6$ & -2.667 & $4.31 \times 10^{-5}$ \\
\hline hsa-miR-191 & $1,337.8$ & 4,112 & - 3.077 & 0.003671 \\
\hline hsa-miR-454 & 11.2 & 36.2 & -3.236 & 0.006250 \\
\hline hsa-miR-10a & $1,765.9$ & $5,748.8$ & -3.257 & $5 \times 10^{-6}$ \\
\hline hsa-miR-195 & 188.2 & 865.9 & -4.608 & 0.008269 \\
\hline hsa-miR-10b & 13.4 & 84.9 & -6.329 & 0.000451 \\
\hline hsa-miR-130a & 451.8 & $2,868.5$ & -6.329 & 0.003837 \\
\hline hsa-miR-374a & 18.1 & 128.8 & -7.092 & 0.000556 \\
\hline hsa-miR-146b-5p & 190.4 & $1,459.9$ & -7.692 & 0.005392 \\
\hline hsa-miR-146a & 129.2 & $1,070.7$ & -8.264 & 0.007859 \\
\hline hsa-miR-181c & 63.9 & 539.1 & -8.403 & 0.001424 \\
\hline hsa-miR-218 & 10 & 99.7 & -10.000 & $3 \times 10^{-7}$ \\
\hline hsa-let-7g & 59 & 611.5 & -10.417 & 0.002014 \\
\hline hsa-miR-15b & 21.5 & 229.2 & -10.638 & 0.001555 \\
\hline hsa-miR-125a-5p & 62.5 & 790.1 & -12.658 & 0.001136 \\
\hline hsa-miR-223 & 79.8 & $1,158.8$ & -14.493 & 0.000837 \\
\hline hsa-miR-99a & 70 & $1,111.4$ & -15.873 & 0.000261 \\
\hline hsa-miR-140-3p & 18.1 & 291.8 & -16.129 & $2.31 \times 10^{-5}$ \\
\hline hsa-miR-126 & 16.7 & $2,71.9$ & -16.393 & $5.67 \times 10^{-5}$ \\
\hline hsa-miR-199b-3p & 136 & $2,517.8$ & -18.519 & 0.003903 \\
\hline hsa-miR-100 & 84.9 & $1,757.3$ & -20.833 & 0.000104 \\
\hline hsa-miR-199a-5p & 35.3 & 782.6 & -22.222 & 0.000256 \\
\hline hsa-miR-125b & 95.3 & $2,992.6$ & -31.250 & $9.91 \times 10^{-5}$ \\
\hline
\end{tabular}

aPresented as the actual change in expression. 
Table 3

MicroRNA differential expression between male breast cancers and male gynecomastia after enrichment for tumor cellularity

\begin{tabular}{|c|c|c|c|c|}
\hline MicroRNA & Cancer normalized & Gynecomastia normalized & Fold change ${ }^{a}$ & $P$ value \\
\hline hsa-miR-499-3p & 300.2 & 17.7 & 16.96 & 0.000361 \\
\hline hsa-miR-129-3p & 124.3 & 10.0 & 12.43 & 0.001482 \\
\hline hsa-miR-330-5p & 322.1 & 66.6 & 4.836 & 0.003715 \\
\hline hsa-miR-10a & 1829.8 & 6683.6 & -3.650 & 0.000353 \\
\hline hsa-miR-191 & 1655.3 & 6552.6 & -3.952 & 0.007160 \\
\hline hsa-miR-338-5p & 17.3 & 106.7 & -6.173 & 0.005437 \\
\hline hsa-miR-218 & 10.0 & 74.6 & -7.463 & 0.000527 \\
\hline hsa-miR-369-3p & 17.5 & 151.8 & -8.674 & 0.002524 \\
\hline hsa-miR-454 & 11.8 & 102.8 & -8.711 & 0.000753 \\
\hline hsa-miR-10b & 15.1 & 132.8 & -8.772 & 0.005204 \\
\hline hsa-miR-374a & 17.6 & 238.3 & -13.514 & 0.000447 \\
\hline hsa-miR-126 & 18.8 & 315.2 & -16.667 & 0.003277 \\
\hline hsa-miR-140-3p & 18.6 & 340.7 & -18.182 & 0.000843 \\
\hline
\end{tabular}

aPresented as the actual change in expression.

\section{Quantitative real-time PCR analysis}

To confirm the results of microarray analysis, we performed quantitative real-time PCR analysis on a limited number of samples (19 cancer samples, five gynecomastia samples) using probes corresponding to miR-125b, miR-126, miR-10b, miR-10a, miR-191, miR-26b, miR-607 and miR-135b (Figure 2 ). The quantitative real-time $P C R$ analysis confirmed the results obtained by microarray analysis. In fact, miR-125b, miR-126, miR-10b, miR-10a and miR-191 were underexpressed whereas miR-26b, miR-607 and miR-135b were overexpressed in cancer samples examined, in comparison with the gynecomastia samples.

\section{Immunohistochemical analysis}

To further confirm our microarray data, and to demonstrate that miRNA analysis may be important in investigations into male breast cancer specific genes, we sought to correlate the expression of significantly deregulated miRNA genes in male breast cancer samples with two of their previously reported targets (Figure 3a). For this purpose, we performed an IHC analysis on the HOXD10 and VEGF genes [14,39].

The HOXD10 gene represses the expression of genes involved in cell migration and extracellular matrix remodeling in breast cancer cells, and it is regulated by miR-10b [14]. Since we observed miR-10b to be downregulated in male breast cancers, we therefore decided to analyze HOXD10 expression in formalin-fixed paraffin-embedded tissue samples

Figure 1

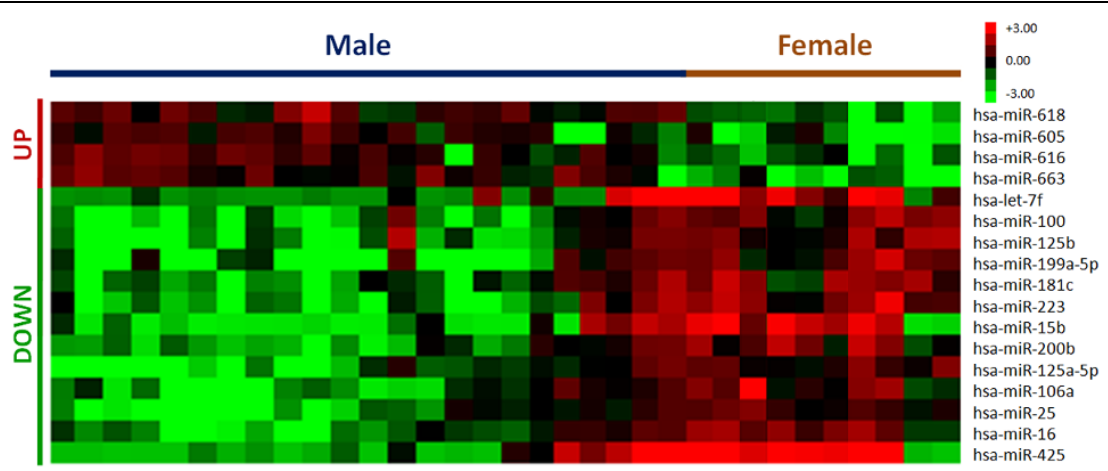

MicroRNA differential expression in male versus female breast cancers. Hierarchical clustering of the 17 microRNA genes with a significantly different expression. Rows, individual genes; columns, individual tissue samples. Pseudocolors indicate transcript levels below, equal to, or above the

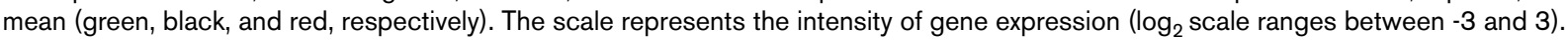


Table 4

\begin{tabular}{|c|c|c|c|c|}
\hline MicroRNA & Male normalized & Female normalized & Fold change $^{a}$ & $P$ value \\
\hline hsa-miR-663 & 492.9 & 77.5 & 6.369 & $7.1 \times 10^{-6}$ \\
\hline hsa-miR-618 & 428.3 & 106.7 & 4.444 & $2.0 \times 10^{-7}$ \\
\hline hsa-miR-605 & 174.0 & 44.4 & 3.922 & 0.000373 \\
\hline hsa-miR-616 & 309.2 & 86.0 & 3.597 & 0.000213 \\
\hline hsa-miR-200b & 147.6 & 642.8 & -4.354 & 0.000144 \\
\hline hsa-miR-181c & 145.9 & 656.1 & -4.500 & 0.000624 \\
\hline hsa-miR-106a & 199.3 & 914.7 & -4.589 & 0.000594 \\
\hline hsa-miR-125a-5p & 131.0 & 697.9 & -5.326 & 0.000698 \\
\hline hsa-miR-16 & 351.6 & 2021.7 & -5.750 & 0.000871 \\
\hline hsa-miR-25 & 309.3 & 1875.1 & -6.062 & 0.000992 \\
\hline hsa-miR-100 & 196.8 & 1206.9 & -6.132 & 0.000160 \\
\hline has-let-7f & 39.0 & 241.4 & -6.186 & 0.000380 \\
\hline hsa-miR-125b & 206.6 & 1427.7 & -6.912 & 0.000513 \\
\hline hsa-miR-15b & 48.7 & 364.5 & -7.108 & 0.000508 \\
\hline hsa-miR-425 & 53.5 & 436.3 & -8.161 & 0.000614 \\
\hline hsa-miR-199a-5p & 84.7 & 710.0 & - 8.387 & 0.000306 \\
\hline hsa-miR-223 & 167.3 & 1414.6 & -8.454 & 0.000111 \\
\hline
\end{tabular}

aPresented as the actual change in expression.

\section{Figure 2}

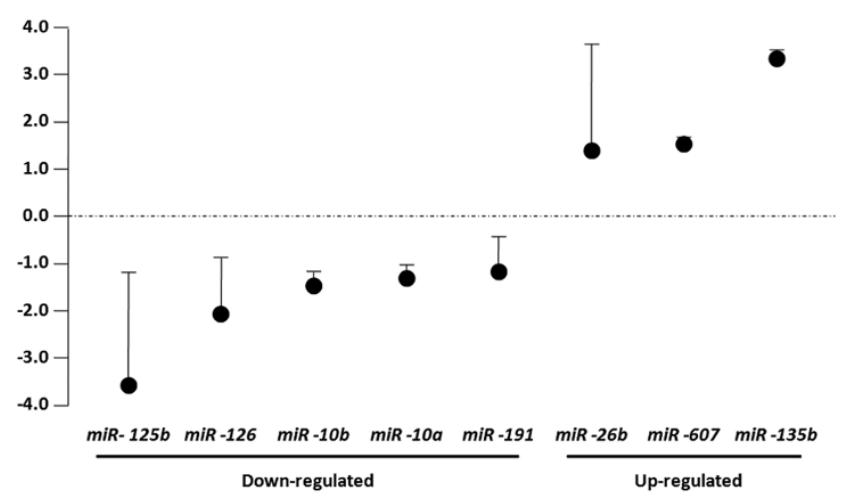

Quantitative real-time PCR validation of microRNA microarray results in male breast cancers. Relative expression of microRNAs in male breast cancer compared with cases of gynecomastia by real-time PCR. miR125b, miR-126, miR-10b, miR-10a and miR-191 were underexpressed in cancer samples, whereas miR-26b, miR-607 and miR-135b were overexpressed. Dots, normalized ratio microRNA gene expression values (breast cancers/gynecomastia); error bars, standard deviation. obtained from 10 male breast cancer patients and five gynecomastia patients. As expected, the five gynecomastia samples showed a weak cytoplasmic HOXD10 IHC positivity, whereas $8 / 10$ male breast cancers samples showed HOXD10 moderate- strong cytoplasmic positivity with membranous reinforcement (Figure $3 b$ to $3 d$ ).

$V E G F$ is a positive regulator of angiogenesis, and its expression is upregulated in many types of cancers, including breast cancers. VEGF is also a target protein of miR-126 [39]. Given the downregulation of miR-126 in male breast cancers, we tested VEGF IHC expression in our series of male breast cancers/gynecomastia. In gynecomastia samples VEGF showed weak cytoplasmic immunoreactions, whereas in 9/10 males a strong cytoplasmic reactivity was observed (Figure $3 \mathrm{e}$ to $3 \mathrm{~g}$ ).

\section{Discussion}

Aberrant miRNA expression patterns have been described in a variety of hematologic and solid-organ malignancies, and several miRNA signatures have also been described for female breast cancer [10-30]. In the present study we have identified a global expression pattern of miRNAs that can differentiate gynecomastia from male breast cancer and can differentiate male breast cancer from female cancers. 


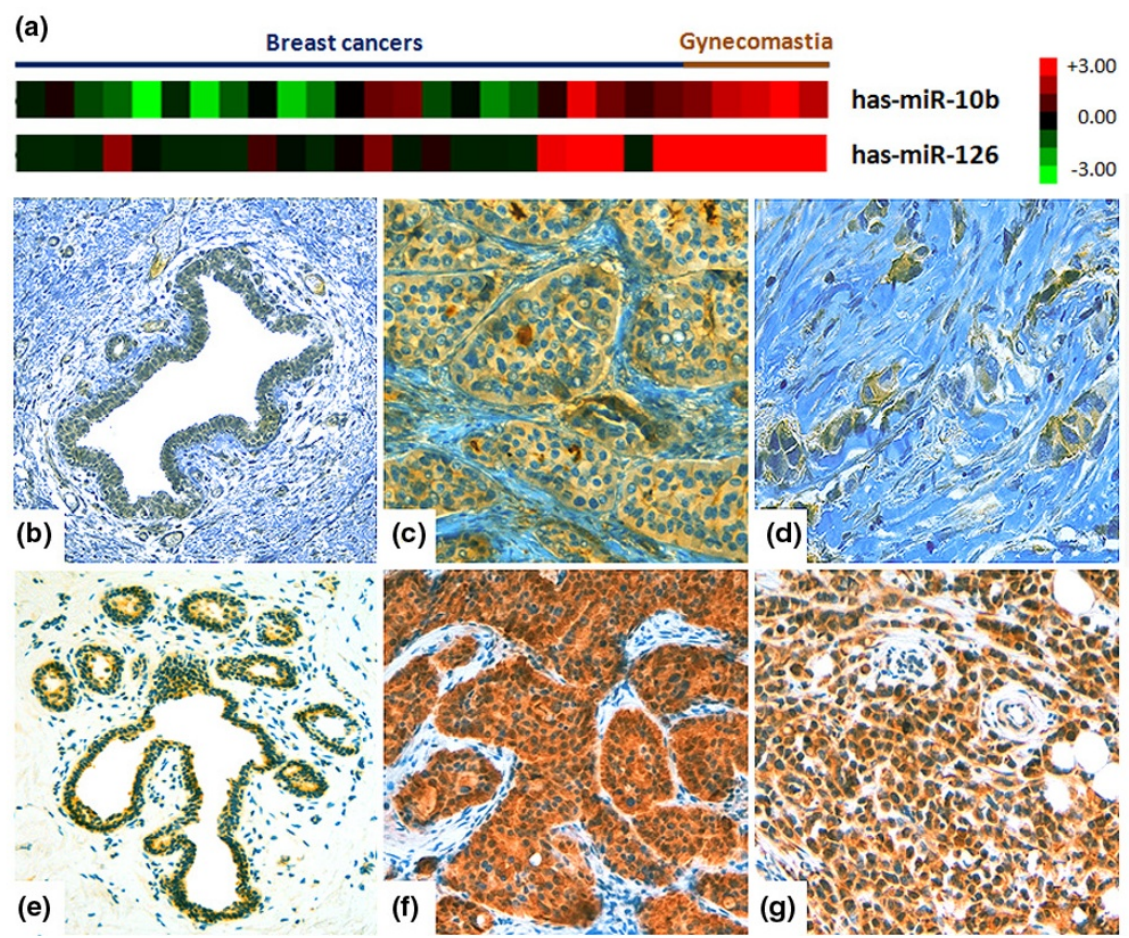

miR-10b and miR126 genes are downregulated in male breast cancers versus gynecomastia. (a) Columns represent individual tissue samples. Pseudocolors indicate transcript levels below, equal to, or above the mean (green, black, and red, respectively). The scale represents the intensity of gene expression ( $\log _{2}$ scale ranges between -3 and 3). Representative examples of (b), (c), (d) homeobox-D10 and (e), (f), (g) vascular endothelial growth factor immunohistochemical expression in male breast cancers and gynecomastia samples. (b) and (e) Weak immunohistochemical staining in gynecomastia samples. (c), (d), (f) and (g) Positive immunoreactions in male breast cancer samples.

Gynecomastia is the most common clinical and pathologic abnormality of the male breast. It results from hypertrophy of breast tissue. Numerous conditions have been associated with gynecomastia, but the pathophysiological bases are due to an imbalance of sex hormones and the tissue responsiveness to them.

Previous studies of miRNA expression in human breast cancer have focused on comparing normal tissues with tumor samples $[10,11,21]$. Because of the absence in men of a normal nonhypertrophic breast gland, we choose to compare gynecomastia with male breast cancer. In fact, gynecomastia has a higher amount of breast epithelium than normal breast. Gynecomastia could therefore be considered a good normal control for male breast cancer.

We identified a miRNA signature for male breast cancer, composed of 43 miRNAs that were differently expressed between tumors and gynecomastia samples. In particular, 17 miRNAs were upregulated and 26 miRNAs were downregulated in cancers (Table 2). Interestingly, in this signature we identified miRNAs that had previously been associated with breast cancers compared with normal tissues. Two overexpressed miRNAs - miR-149 [10] and miR-29b [12,21,22] - have already been described as upregulated in other female breast cancer studies. On the other hand, miR-145 [10,20], miR-10b [10], let-7g [19], miR-125a-5p [10,31], miR-125b [31] and miR126 [40] have been described as downregulated.

According to previous reports in female breast carcinogenesis, the most interesting and promising miRNAs of this male breast cancer signature are miR-10b, miR-126, miR-125a-5p and miR-125b $[14,31,40]$.

miR-10b has been previously described as downregulated in female breast cancer compared with normal tissue [10], but it has been also associated with the induction of tumor invasion and metastasis of breast cancer derived cells by targeting HOXD10 [14]. The downregulation of HOXD10 permits subsequently the expression of the prometastatic gene product $R H O C$, favoring, in turn, cancer cell migration and invasion [14]. Gee and colleagues, however, showed that miR-10b is not significantly associated with breast cancer metastasis in a large series of early-stage breast cancers [41].

We observed in our tumor samples a downregulation of miR125a-5p, miR-125b, miR-126, miR-145 and let-7g genes, which have been shown to be related to hormonal settings and 
ErbB2 status of the tumor: miR-125a-5p and miR-125b downregulate ErbB2 and ErbB3 expression [31], miR-126 and let$7 \mathrm{~g}$ are upregulated in ErbB2-negative tumors, whereas miR145 is upregulated in ErbB2-negative tumors and upregulated in estrogen-receptor-positive and progesterone-receptor-positive tumors [13].

Our IHC study supports previous reports on the relationship of miR-10b and miR-126 and their respective gene targets $[14,39]$. Larger prospective studies are needed to confirm our $\mathrm{IHC}$ data, but we have further suggested that miRNA profiling may be helpful in the discovery of new breast cancer gene targets.

Although our tumor samples were partially microdissected, contamination with surrounding stromal tissue is inevitable. For this reason we performed an enrichment analysis of our data considering the amount of tumor tissue analyzed (Table 3). In this analysis, we observed that two miRNAs - miR-499$3 p$ and miR-330-5p - were upregulated in cancer samples and followed the enrichment, suggesting they are key miRNAs in male breast cancer. Because these two miRNAs have not yet been associated with cancer development, we are planning to test their possible role in breast cell transformation with functional studies. Other miRNAs similarly altered after the enrichment, such as miR-191, miR-454, miR-10a, miR-374a, miR-10b, miR-218, miR-140-3p and miR-126, were downregulated in cancer. This group of miRNAs could also be important in the transformation of male breast cells. On the other hand, one could question whether these miRNAs are basically expressed in normal stromal cells and the enrichment is only a secondary effect to the loss of the stromal counterpart.

Of interest, from a histological point of view, male breast cancer is usually an invasive ductal carcinoma [35]. This histotype specificity seems one of the major differences between male and female breast cancer biology. We therefore analyzed the miRNA expression profiles of male/female breast cancer samples, looking for miRNAs differentially expressed between the two clinical categories. We identified 17 deregulated miRNAs (Table 4). Further studies considering large series of male/ female breast tumors need to be conducted to address a possible role of miRNAs concerning the biological and prognostic tumor characteristics.

\section{Conclusions}

The present report provides the first study on miRNA expression in male breast cancer. Considering gynecomastia as a potentially benign counterpart of male breast glands, we identified miRNAs that are differentially expressed between cancer and gynecomastia. Moreover, we investigated the differences between miRNA gene expression profiles in male versus female breast cancers.
The functional significance of miRNA dysregulation we have shown needs to be further investigated. Our results suggest that specific miRNAs may be directly involved in male breast cancer development and that they may represent a novel diagnostic tool in the characterization of specific cancer gene targets.

\section{Competing interests}

The authors declare that they have no competing interests.

\section{Authors' contributions}

All authors directly participated in the planning and execution of the study, and read and approved the final version of the manuscript.

\section{Acknowledgements}

The authors would like to acknowledge the continuous support of the Benjamin Perkins Bladder Cancer Fund and the Martin Greitzer Fund. The authors are grateful to Valentina Zoccoletto, Vincenza Guzzardo, Vanni Lazzarin and Cristiano Lanza for their technical assistance.

\section{References}

1. Jemal A, Siegel R, Ward E, Hao Y, Xu J, Murray T, Thun MJ: Cancer statistics, 2008. CA Cancer J Clin 2008, 58:71-96.

2. Ravandi-Kashani F, Hayes TG: Male breast cancer: a review of the literature. Eur J Cancer 1998, 34:1341-1347.

3. Liu CG, Calin GA, Meloon B, Gamliel N, Sevignani C, Ferracin M, Dumitru CD, Shimizu M, Zupo S, Dono M, Alder H, Bullrich F, Negrini $M$, Croce CM: An oligonucleotide microchip for genome-wide microRNA profiling in human and mouse tissues. Proc Natl Acad Sci USA 2004, 101:9740-9744.

4. Calin GA, Liu CG, Sevignani C, Ferracin M, Felli N, Dumitru CD, Shimizu M, Cimmino A, Zupo S, Dono M, Dell'Aquila ML, Alder H, Rassenti L, Kipps TJ, Bullrich F, Negrini M, Croce CM: MicroRNA profiling reveals distinct signatures in $B$ cell chronic lymphocytic leukemias. Proc Natl Acad Sci USA 2004, 101:11755-11760.

5. Bartel DP: MicroRNAs: genomics, biogenesis, mechanism, and function. Cell 2004, 116:281-297.

6. Negrini M, Ferracin M, Sabbioni S, Croce CM: MicroRNAs in human cancer: from research to therapy. J Cell Sci 2007 , 120:1833-1840.

7. Calin GA, Croce CM: MicroRNA signatures in human cancers. Nat Rev Cancer 2006, 6:857-866.

8. Calin GA, Croce CM: MicroRNA-cancer connection: the beginning of a new tale. Cancer Res 2006, 66:7390-7394.

9. Khoshnaw SM, Green AR, Powe DG, Ellis IO: MicroRNA involvement in the pathogenesis and management of breast cancer. $J$ Clin Pathol 2009, 62:422-428.

10. Iorio MV, Ferracin M, Liu CG, Veronese A, Spizzo R, Sabbioni S, Magri E, Pedriali M, Fabbri M, Campiglio M, Menard S, Palazzo JP, Rosenberg A, Musiani P, Volinia S, Nenci I, Calin GA, Querzoli P, Negrini M, Croce CM: MicroRNA gene expression deregulation in human breast cancer. Cancer Res 2005, 65:7065-7070.

11. Blenkiron C, Goldstein LD, Thorne NP, Spiteri I, Chin SF, Dunning MJ, Barbosa-Morais NL, Teschendorff AE, Green AR, Ellis IO, Tavare' S, Caldas C, Miska EA: MicroRNA expression profiling of human breast cancer identifies new markers of tumour subtype. Genome Biol 2007, 8:R214.

12. Volinia S, Calin GA, Liu CG, Ambs S, Cimmino A, Petrocca F, Visone $R$, lorio $M$, Roldo C, Ferracin M, Prueitt RL, Yanaihara N, Lanza G, Scarpa A, Vecchione A, Negrini M, Harris CC, Croce $\mathrm{CM}$ : A microRNA expression signature of human solid tumors defines cancer gene targets. Proc Natl Acad Sci USA 2006, 103:2257-2261.

13. Mattie MD, Benz CC, Bowers J, Sensinger K, Scott GK, Fedele V, Ginzinger D, Getts R, Haqq C: Optimized high-throughput microRNA expression profiling provides novel biomarker 
assessment of clinical prostate and breast cancer biopsies. Mol Cancer 2006, 5:24.

14. Ma L, Teruya-Feldstein J, Weinberg RA: Tumour invasion and metastasis initiated by microRNA-10b in breast cancer. Nature 2007, 449:682-689.

15. Silveri L, Tilly G, Vilotte JL, Le Provost F: MicroRNA involvement in mammary gland development and breast cancer. Reprod Nutr Dev 2006, 46:549-556.

16. Lehmann U, Hasemeier B, Christgen M, Mueller M, Roemermann $\mathrm{D}$, Laenger $\mathrm{F}$, Kreipe $\mathrm{H}$ : Epigenetic inactivation of microRNA gene hsa-mir-9-1 in human breast cancer. J Pathol 2008, 214:17-24

17. Frankel LB, Christoffersen NR, Jacobsen $A$, Lindow $M$, Krogh $A$, Lund $\mathrm{AH}$ : Programmed cell death 4 (PDCD4) is an important functional target of the microRNA miR-21 in breast cancer cells. J Biol Chem 2008, 283:1026-1033.

18. Martens-Talcott SU, Chintharlapalli S, Li X, Safe S: The oncogenic microRNA-27a targets genes that regulate specificity protein transcription factors and the G2-M checkpoint in MDAMB-231 breast cancer cells. Cancer Res 2007, 67:11001-11011.

19. Yu F, Yao H, Zhu P, Zhang X, Pan Q, Gong C, Huang Y, Hu X, Su $F$, Lieberman J, Song E: let-7 regulates self renewal and tumorigenicity of breast cancer cells. Cell 2007, 131:1109-1123.

20. Sempere LF, Christensen M, Silahtaroglu A, Bak M, Heath CV, Schwartz G, Wells W, Kauppinen S, Cole CN: Altered microRNA expression confined to specific epithelial cell subpopulations in breast cancer. Cancer Res 2007, 67:11612-11620.

21. Yan LX, Huang XF, Shao Q, Huang MY, Deng L, Wu QL, zeng YX, Shao JY: MicroRNA miR-21 overexpression in human breast cancer is associated with advanced clinical stage, lymph node metastasis and patient poor prognosis. RNA 2008, 14:2348-2360

22. Zhao JJ, Lin J, Yang H, Kong W, He L, Ma X, Coppola D, Cheng JQ: MicroRNA-221/222 negatively regulates $E R \alpha$ and associates with tamoxifen resistance in breast cancer. $J$ Biol Chem 2008, 283:31079-31086.

23. Foekens JA, Sieuwerts AM, Smid M, Look MP, de Weerd V, Boersma AW, Klijn JG, Wiemer EA, Martens JW: Four miRNAs associated with aggressiveness of lymph node-negative, estrogen receptor-positive human breast cancer. Proc Natl Acad Sci USA 2008, 105:13021-13026.

24. Miller TE Ghoshal K, Ramaswamy B, Roy S, Datta J, Shapiro CL, Jacob S, Majumder S: MicroRNA-221/222 confers tamoxifen resistance in breast cancer by targeting p27(Kip1). J Biol Chem 2008, 283:29897-29903.

25. Yu Z, Wang C, Wang M, Li Z, Casimiro MC, Liu M, Wu K, Whittle J, Ju X, Hyslop T, McCue P, Pestell RG: A cyclin D1/microRNA $17 / 20$ regulatory feedback loop in control of breast cancer cell proliferation. J Cell Biol 2008, 182:509-517.

26. Shen J, Ambrosone CB, DiCioccio RA, Odunsi K, Lele SB, Zhao $\mathrm{H}$ : A functional polymorphism in the miR-146a gene and age of familial breast/ovarian cancer diagnosis. Carcinogenesis 2008, 29:1963-1966.

27. Kovalchuk O, Filkowski J, Meservy J, Inytskyy Y, Tryndyak VP, Chekhun VF, Pogribny IP: Involvement of microRNA-451 in resistance of the MCF-7 breast cancer cells to chemotherapeutic drug doxorubicin. Mol Cancer Ther 2008, 7:2152-2159.

28. Kondo N, Toyama T, Sugiura H, Fujii Y, Yamashita H: miR-206 expression is down-regulated in estrogen receptor alpha-positive human breast cancer. Cancer Res 2008, 68:5004-5008.

29. Verghese ET, Hanby AM, Speirs V, Hughes TA: Small is beautiful: microRNAs and breast cancer-where are we now? J Pathol 2008, 215:214-221.

30. Camps C, Buffa FM, Colella S, Moore J, Sotiriou C, Sheldon $\mathrm{H}$, Harris AL, Gleadle JM, Ragoussis J: hsa-miR-210 is induced by hypoxia and is an independent prognostic factor in breast cancer. Clin Cancer Res 2008, 14:1340-1348.

31. Scott GK, Goga A, Bhaumik D, Berger CE, Sullivan CS, Benz CC: Coordinate suppression of ERBB2 and ERBB3 by enforced expression of micro-RNA miR-125a or miR-125b. J Biol Chem 2007, 282:1479-1486.

32. Tavazoie SF, Alarcon C, Oskarsson T, Padua D, Wang O, Bos PD, Gerald WL, Massague J: Endogenous human microRNAs that suppress breast cancer metastasis. Nature 2008, 451:147-152.
33. Huang $Q$, Gumireddy K, Schrier M, Le Sage C, Nagel R, Nair S, Egan DA, Li A, Huang G, Klein-Szanto AJ, Gimotty PA, Katsaros D, Coukos G, Zhang L, Pure E, Agami R: The microRNAs miR-373 and $\mathrm{miR}-520 \mathrm{c}$ promote tumour invasion and metastasis. Nat Cell Biol 2008, 10:202-210.

34. Tili E, Michaille JJ, Gandhi V, Plunkett W, Sampath D, Calin GA: miRNAs and their potential for use against cancer and other diseases. Future Oncol 2007, 3:521-537.

35. Ciocca V, Bombonati A, Gatalica Z, Di Pasquale M, Milos A, RuizOrrico A, Dreher D, Folch N, Monzon F, Santeusanio G, Perou CM, Bernard PS, Palazzo JP: Cytokeratin profiles of male breast cancers. Histopathology 2006, 49:365-370.

36. Bloomston M, Frankel WL, Petrocca F, Volinia S, Alder H, Hagan JP, Liu CG, Bhatt D, Taccioli C, Croce CM: MicroRNA expression patterns to differentiate pancreatic adenocarcinoma from normal pancreas and chronic pancreatitis. JAMA 2007, 297:1901-1908.

37. Wright GW, Simon R: A random variance model for detection of differential gene expression in small microarray experiments. Bioinformatics 2003, 19:2448-2455.

38. Tusher VG, Tibshirani R, Chu G: Significance analysis of microarrays applied to the ionizing radiation response. Proc Nat Acad Sci USA 2001, 98:5116-5121.

39. Liu B, Peng XC, Zheng XL, Wang J, Qin YW: MiR-126 restoration down-regulate VEGF and inhibit the growth of lung cancer cell lines in vitro and in vivo. Lung Cancer 2009 in press.

40. Zhang J, Du YY, Lin YF, Chen YT, Yang L, Wang HJ, Ma D: The cell growth suppressor, mir-126, targets IRS-1. Biochem Biophys Res Commun 2008, 377:136-140.

41. Gee HE, Camps C, Buffa FM, Colella S, Sheldon H, Gleadle JM, Ragoussis J, Harris AL: MicroRNA-10b and breast cancer metastasis. Nature 2008, 455:E8-E9. 